\title{
MVPP chemotherapy regimen for advanced Hodgkin's disease
}

\author{
S B SUTCLIFFE, P F.M WRIGLEY, J PETO, T A LISTER, A G STANSFELD, \\ J M A WHITEHOUSE, D CROWTHER, J S MALPAS
}

combination of drugs known to be individually effectivenamely, mustine, vincristine, procarbazine, and prednisolone (MOPP). ${ }^{1}$ The efficacy of this regimen was confirmed, and the characteristics and toxicity are now well appreciated. ${ }^{2-5}$ In 1968 a modified regimen, MVPP $^{6}$ (mustine, vinblastine, procarbazine, and prednisolone), was introduced in an attempt to avoid the neurological and haematological toxicity of MOPP. We describe the outcome of a trial in which 133 patients admitted to hospital between January 1968 and December 1972 received treatment with MVPP. All were followed up until the end of 1976, 19 patients who were admitted towards the end of 1972 being followed up for only four years.

\section{Patients and methods}

Patients with histologically proved HD were staged clinically according to set guidelines.' Ages ranged from 8 to 72 years. Histological sections were examined (AGS) and classified according to the Rye nomenclature. ${ }^{8}$ Patients with clinical stage I-IIIA disease were restaged after exploratory laparotomy and splenectomy. ${ }^{9}$ All patients with stage IIIB or IV disease received MVPP chemotherapy. Three treatment groups were defined-namely, (1) patients who had not previously received treatment (49 cases); (2) patients who had received previous radiotherapy (42); and (3) patients who had received previous chemotherapy with or without radiotherapy (42).

Twenty-five patients with lesser stage disease were also treated with the regimen. Seven had had no previous treatment (stage IIB two patients, stage IIIA five patients) and were given chemotherapy because of difficulty in determining the extent of the disease (two patients), medical complications (one), delay in administering treatment because of operative complications (one), refusal to undergo irradiation (two), or alteration in staging of the disease after treatment had begun (one). Fifteen patients had been irradiated but owing to relapse in the irradiated area could have received only palliative irradiation (stage IIA two patients, stage IIB three patients, stage IIIA 10 patients). Three patients had relapsed after radiotherapy and single-agent chemotherapy and could not receive further irradiation (stage IIA two patients, stage IIIA one patient).

MVPP regimen-The MVPP regimen consisted of mustine 6 $\mathrm{mg} / \mathrm{m}^{2}$ and vinblastine $6 \mathrm{mg} / \mathrm{m}^{2}$ on days 1 and 8 , and procarbazine $100 \mathrm{mg} / \mathrm{m}^{2}$ and prednisolone $40 \mathrm{mg}$ by mouth on days $1-15$ of every course. The treatment-free interval between successive courses was four weeks. Vinblastine was substituted for vincristine to reduce neurotoxicity. Originally vinblastine was also given on day 15 , but this was deleted from the regimen in 1971 as haematological toxicity prevented its application in most cases. The cycle was lengthened to six weeks to overcome the haematological toxicity associated with MOPP. Six courses of MVPP were administered to induce remission. If the disease progressed despite MVPP chemotherapy other treatment was substituted. Seventy-eight patients who achieved complete remission were entered into an MRC maintenance study comparing cyclical two-drug (vinblastine and procarbazine) with cyclical four-drug (MVPP) treatment. Thirteen patients received no maintenance treatment.

Remission assessment-Patients were considered to be in complete clinical remission when there were no symptoms or clinical signs of the disease and chest radiographs and a pedal lymphogiam were normal. Blood tests had to yield results within normal limits, including an erythrocyte sedimentation rate of less than $30 \mathrm{~mm}$ in the first hour. Extranodal sites at diagnosis were biopsied again as appropriate after treatment to assess remission. Patients were classified as having achieved or failed to achieve complete remission after adequate chemotherapy. Those achieving partial remission were thus classified as "non-remitters."

\section{Christie Hospital, Manchester M20 9BX}

D CROWTHER, PHD, FRCP, professor of medical oncology 
Statistical analysis-In all analyses the durations of survival and remission were measured from the day of entry to the trial. Survival curves and five-year survival and disease-free survival rates were calculated by means of actuarial analysis. When five-year survival rates were compared the associated significance level was based on the log-rank test, which compares the entire survival curves and not just the difference at five years. ${ }^{10}$ The remission rate is the proportion of patients ever achieving complete remission; for certain analyses, however, the one-year remission rate (the proportion surviving in complete remission at one year) is also given.

\section{Results}

Analyses of duration of remission and some survival rates are based on only those patients surviving in first complete remission one year after starting treatment. Survival rates based on this group are thus considerably higher than the overall rates based on all patients including those with late or no remission.

\section{SURVIVAL}

Table I shows the numbers of patients achieving complete remission in each treatment group. Complete remission was eventually achieved in $38(90 \%)$ of the patients who had received radiotherapy and 37 $(76 \%)$ of the untreated patients. The combined remission rate $(82 \%$ was significantly higher than the rate of $40 \%$ for patients who had received prior chemotherapy ( $P=0 \cdot 01)$. The corresponding five-year survival rates were $86 \%$ for previously irradiated patients, $65 \%$ for untreated patients, and only $33 \%$ for patients who had received previous chemotherapy (fig 1). The projected median survival for patients who did not receive chemotherapy will be about 12 years, provided that mortality in these patients remains at the observed level of $6 \%$ a year.

TABLE I-Survival of patients according to previous treatment

\begin{tabular}{|c|c|c|c|}
\hline Previous treatment & No in group & $\begin{array}{c}\text { Actual No }(0 \%) \\
\text { attaining complete } \\
\text { remission }\end{array}$ & $\begin{array}{c}\text { Actuarial } \\
\text { survival at } \\
\text { five years }\left({ }_{0}{ }_{0}\right)\end{array}$ \\
\hline $\begin{array}{l}\text { None } \\
\text { Radiotherapy } \\
\text { Chemotherapy }\end{array}$ & $\begin{array}{l}49 \\
42 \\
42\end{array}$ & $\begin{array}{l}37(76) \\
38(90) \\
17(40)\end{array}$ & $\begin{array}{l}65 \\
86 \\
33\end{array}$ \\
\hline
\end{tabular}

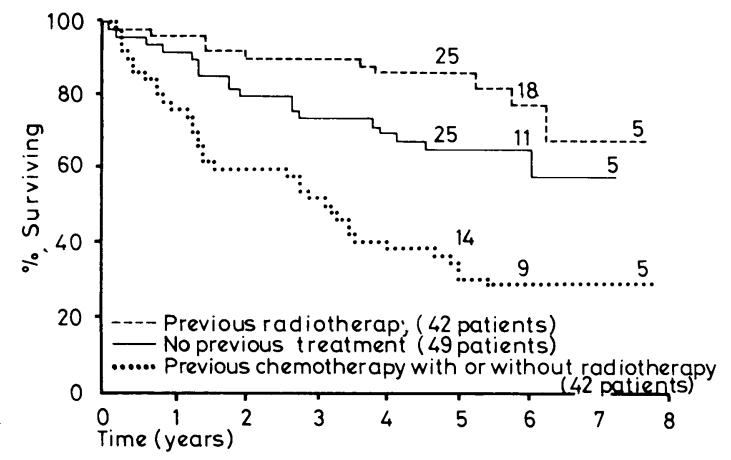

FIG 1-Actuarial survival (actual numbers also given) of patients grouped according to previous treatment.

DISEASE-FREE SURVIVAL AMONG PATIENTS IN REMISSION AT ONE YEAR

Patients who had received chemotherapy had a lower remission rate than those in other groups. Furthermore, on achieving remission they had a lower disease-free survival rate $(46 \%$ at five years compared with $70 \%$ for the untreated group and $75 \%$ for the irradiated group; fig 2 ) and a lower survival rate $(62 \%$ at five years compared with $87 \%$ and $97 \%$ for untreated and irradiated patients respectively; table II).

Patients who had received chemotherapy were excluded from the analyses of prognostic factors. They constituted a selected population

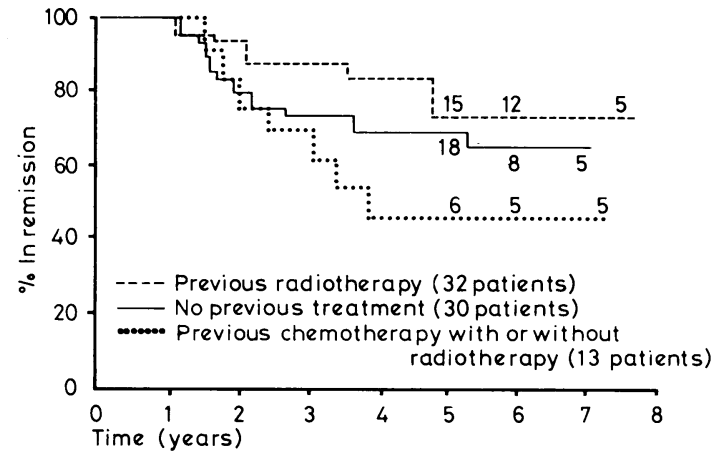

FIG 2-Actuarial disease-free survival of patients in remission at one year (actual numbers also given).

TABLE II-Survival and disease-free survival rates after five years among patients in remission at one year

\begin{tabular}{l|c|c|c}
\hline \multicolumn{1}{|c|}{ Previous treatment } & $\begin{array}{c}\text { No in } \\
\text { remission at } \\
\text { one year }\end{array}$ & $\begin{array}{c}\text { Actuarial } \\
\text { survival at } \\
\text { five years (".) }\end{array}$ & $\begin{array}{c}\text { Actuarial } \\
\text { disease-free } \\
\text { survival at } \\
\text { five years (\%) }\end{array}$ \\
\hline $\begin{array}{l}\text { None } \\
\text { Radiotherapy }\end{array}$ & 30 & 87 & 70 \\
Chemotherapy & 32 & 97 & 75 \\
\hline
\end{tabular}

with progressive advanced disease existing before the introduction of $\frac{\widehat{\widehat{S}}}{\supset}$ combination chemotherapy; as such they were not representative of $\vec{\epsilon}$ any group of patients being treated by current methods. Their inferior prognosis was related to the predominance of advanced-stage disease $(76 \%$ stage IVB compared with $35 \%$ in the other groups) and the inability to treat $25 \%$ of them effectively because of bone marrow depression.

The difference in prognosis between untreated and irradiated patients (five-year survival rates $65 \%$ and $86 \%$ respectively; $\mathrm{P}<0.05$ ) reflects the difference in remission rates $(76 \%$ and $90 \%$ respectively; table I). This was due both to the higher proportion of older patients in the untreated group $(71 \%$ under 40 in the irradiated group compared with only $53 \%$ in the untreated group) and the predominance of advanced disease $(21 \%$ with stage IVB in the irradiated group $\overrightarrow{0}$ compared with $47 \%$ in the untreated patients; $\mathrm{P}<0.05)$. After remission had been achieved, however, there was little difference in disease-free survival between the untreated and irradiated groups (disease-free survival at five years $70 \%$ and $75 \%$ respectively). These groups were therefore combined in subsequent analyses to assess the importance of other prognostic factors.

\section{PROGNOSTIC SIGNIFICANCE OF VARIABLES}

Patients who had received chemotherapy were excluded from this $\frac{7}{2}$ analysis. The overall complete remission and survival rates for the remaining patients are given in table III according to histology, sex, $\mathbb{O}$ age, and stage of the disease. Table IV gives the corresponding $\mathrm{N}$ survival and disease-free survival rates for patients in remission at one year.

Stage of disease-Patients with stage IVB disease fared considerably worse than those with lesser stages due to their lower remission rate $\&$ $(66 \%$ compared with $86-100 \%$ for stages IIIA, IIIB, and IVA; $\mathrm{P}<0.01)$. This was reflected in their reduced survival rate $(62 \%$ at five years compared with $67-89 \%$ for the remainder; $\mathrm{P}<0.05$; table III). Allowance for correlation with age did not diminish the significance. After achieving remission, however, their survival and $\varrho$ duration of remission were similar to those of other patients (table IV).

Histology-The remission rate declined with progression of histological type from lymphocyte-predominant to lymphocytedepleted. This apparent trend was not significant, however, perhaps because of the small numbers of patients in the extreme groups. There was no indication that histological type influenced survival or duration of remission (tables III and IV).

Age-Patients aged under 40 had a slightly higher chance of achieving complete remission, although the difference was not 
TABLE III-Effects of histology, sex, age, and stage of disease on prognosis

\begin{tabular}{|c|c|c|c|c|c|c|c|c|c|c|c|c|c|}
\hline & \multirow{2}{*}{ Total } & \multicolumn{4}{|c|}{ Histology } & \multicolumn{2}{|c|}{ Sex } & \multicolumn{2}{|c|}{ Age in years } & \multicolumn{4}{|c|}{ Stage of disease } \\
\hline & & LP & NS & MC & LD & M & F & $<40$ & $>40$ & $<$ IIIB & IIIB & IVA & IVB \\
\hline $\begin{array}{l}\text { No of patients } \\
\text { Actual No (") achieving remission } \\
\text { Actuarial survival at five years (", })\end{array}$ & $\begin{array}{l}91^{*} \\
75(82) \\
75\end{array}$ & $\begin{array}{r}8 \\
83 \\
63\end{array}$ & $\begin{array}{l}48 \\
41 \\
81\end{array}$ & $\begin{array}{l}25 \\
20 \\
72\end{array}$ & $\begin{array}{l}10 \\
6(60) \\
60\end{array}$ & $\begin{array}{l}56 \\
48 \\
73\end{array}$ & $\begin{array}{l}35 \\
27(77) \\
77\end{array}$ & $\begin{array}{l}56 \\
49 \\
84\end{array}$ & $\begin{array}{l}35 \\
26(74) \\
60\end{array}$ & $\begin{array}{l}21 \\
18(86) \\
81\end{array}$ & $\begin{array}{l}26 \\
24 \\
89\end{array}$ & $\begin{array}{l}12 \\
12(100) \\
67\end{array}$ & $\begin{array}{l}32 \\
21(66) \\
62\end{array}$ \\
\hline
\end{tabular}

*Patients who had received previous chemotherapy were excluded.
$\mathrm{LP}=$ Lymphocyte-predominant. $\quad \mathrm{NS}=$ Nodular sclerosis. $\quad \mathrm{MC}=$ Mixed cellularity. $\quad$ LD $=$ Lymphocyte-depleted.

TABLE IV-Effects of histology, sex, age, and stage of disease on prognosis among patients in remission at one year

\begin{tabular}{|c|c|c|c|c|c|c|c|c|c|c|c|c|c|}
\hline & \multirow{2}{*}{ Total } & \multicolumn{4}{|c|}{ Histology } & \multicolumn{2}{|c|}{ Sex } & \multicolumn{2}{|c|}{ Age in years } & \multicolumn{4}{|c|}{ Stage of disease } \\
\hline & & LP & NS & $\mathrm{MC}$ & LD & $M$ & $\mathrm{~F}$ & $<40$ & $\geqslant 40$ & $<$ IIIB & IIIB & IVA & IVB \\
\hline $\begin{array}{l}\text { No of patients } \\
\text { Actuarial disease-free survival at five } \\
\text { years ("o) }\end{array}$ & $62^{*}$ & 67 & 39 & 82 & $\begin{array}{r}4 \\
67\end{array}$ & 35 & $\begin{array}{l}27 \\
74\end{array}$ & 43 & $\begin{array}{l}19 \\
67\end{array}$ & 83 & 71 & 11 & 74 \\
\hline Actuarial survival at five years $(", 1)$ & 92 & 67 & 95 & 92 & 100 & 89 & 96 & 98 & 79 & 94 & 100 & 64 & 100 \\
\hline
\end{tabular}

*Patients who had received previous chemotherapy were excluded.
LP $=$ Lymphocyte-predominant. $\mathrm{NS}=$ Nodular sclerosis. $\quad \mathrm{MC}=$ Mixed cellularity. $\quad$ LD $=$ Lymphocyte-depleted.

significant $(88 \%$ compared with $74 \%$ for patients aged 40 and over; table III). The age of patients in remission at one year did not noticeably affect the proportion still in remission after five years $(76 \%$ of those under 40 compared with $67 \%$ aged 40 and over; table IV); nevertheless, the probability of surviving five years was significantly higher in younger patients $(98 \%$ compared with $79 \%$; $\mathbf{P}<0.01)$. This reflected their lower mortality after relapse. When patients who failed to remit were included the overall five-year survival rate showed a significant dependence on age $(84 \%$ for those under 40 compared with $60 \%$ for those aged 40 and over; $\mathrm{P}<0.01$; table III). This association remained after adjustment for stage.

Symptoms-The prognostic effect of symptoms at the time of entry-that is, fever, night sweats, weight loss-could be assessed only in patients with stage IV disease due to the small number of asymptomatic patients with a lesser stage. The remission rate was marginally lower in symptomatic patients, but the overall survival and duration of first remission showed no consistent relation with the presence of symptoms.

\section{PROGNOSTIC SIGNIFICANCE OF REMISSION}

Figure 3 shows the subsequent survival of patients who were still alive after one year and compares those who had achieved remission by one year with those who had not. The difference in prognosis was highly significant $(P<0.001)$ despite the exclusion of patients who died within the first year and the inclusion among the non-remitters of 13 patients who achieved remission after the first year.

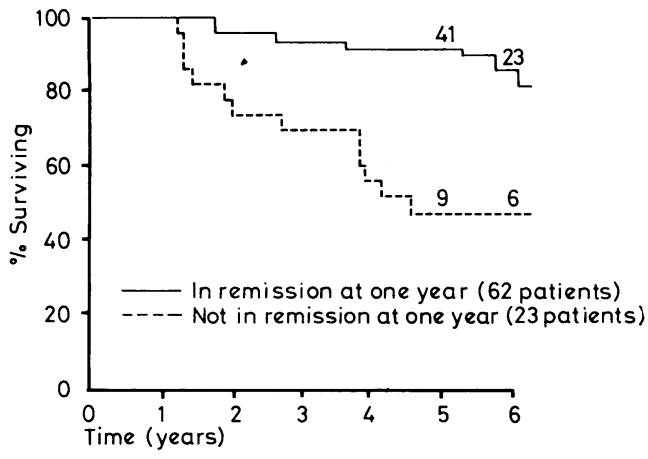

FIG 3-Actuarial survival (actual numbers also given) of patients who had not received previous chemotherapy grouped according to remission status at one year.

\section{SECOND REMISSION}

Thirty-eight patients relapsed after successful induction chemotherapy. A second complete remission was achieved in $13(34 \%)$ with the same regimen or with vincristine substituted for vinblastine. Two other patients achieved a second remission after radiotherapy for localised recurrence.

\section{TOXICITY}

The treatment was generally well tolerated. Intravenous chemotherapy was initially given on an inpatient basis, but subsequent administration was to outpatients in a day ward, which is our current practice. Nausea and vomiting for up to six hours after intravenous administration was almost universal, although it was more severe after the day 1 than day 8 injections. Noticeable alopecia was uncommon. Symptomatic neuropathy manifested as paraesthesiae of fingers and toes. Loss of tendon reflexes was common. Neuropathy did not account for any appreciable morbidity, however, or cause any patient to withdraw from treatment. Total intolerance culminating in refusal occurred in only one case. Advice on probable infertility was offered but was not a cause of the refusal.

Details of the patients receiving chemotherapy are given in table $\mathrm{V}$. Ten patients who had received chemotherapy had progressive disease, which necessitated a change from MVPP chemotherapy. The medians and ranges of haematological values in these 10 patients were haemoglobin $7 \cdot 5(6 \cdot 0-9 \cdot 5) \mathrm{g} / \mathrm{dl}$, white cell count $1.5(0 \cdot 4-3.5) \times 10^{9} / 1$, and platelets $54(12-95) \times 10^{9} / 1$. The difficulty in giving effective

TABLE V-Toxicity of MVPP regimen in patients grouped according to previous treatment

\begin{tabular}{|c|c|c|c|}
\hline & $\begin{array}{l}\text { No previous } \\
\text { treatment }\end{array}$ & $\begin{array}{l}\text { Previous } \\
\text { radiotherapy }\end{array}$ & $\begin{array}{c}\text { Previous } \\
\text { chemotherapy } \\
\text { with or without } \\
\text { radiotherapy }\end{array}$ \\
\hline $\begin{array}{l}\text { No in group } \\
\text { No ( } \%) \text { of patients with disease } \\
\text { progression despite MVPP } \\
\text { regimen }\end{array}$ & $\begin{array}{l}49 \\
3(6)\end{array}$ & $\begin{array}{l}42 \\
1(2)\end{array}$ & $\begin{array}{l}42 \\
10(24)\end{array}$ \\
\hline $\begin{array}{l}\text { No (\%) completing six courses } \\
\text { of MVPP regimen }\end{array}$ & $40(82) \dagger$ & $40(95) \ddagger$ & $28(67) \S$ \\
\hline $\begin{array}{l}\text { No }(\%) \text { observing six-weekly } \\
\text { cycle }\end{array}$ & $38(95)$ & $34(85)$ & $19(68)$ \\
\hline $\begin{array}{l}\text { No }(\%) \text { receiving } \\
\text { recommended drug and } \\
\text { dosage }\end{array}$ & $26(65)$ & $23(58)$ & $18(64)$ \\
\hline $\begin{array}{l}\text { Median haemoglobin (range) } \\
(\mathrm{g} / \mathrm{dl})^{*}\end{array}$ & $10 \cdot 6(5 \cdot 0-14 \cdot 6)$ & $11 \cdot 4(7 \cdot 0-14 \cdot 4)$ & $10 \cdot 2(6 \cdot 0-12 \cdot 8)$ \\
\hline $\begin{array}{l}\text { Median white cell count (range) } \\
\left(\times 10^{-9} / 1\right)^{*}\end{array}$ & $3 \cdot 2(0 \cdot 2-12 \cdot 0)$ & $2 \cdot 1(0 \cdot 4-12 \cdot 0)$ & $2 \cdot 2(0-5 \cdot 5)$ \\
\hline Median platelet count (range) & $150(12-440)$ & $140(18-410)$ & $130(8-330)$ \\
\hline
\end{tabular}

*Recorded at any time during nine months' induction chemotherapy.

Insufficient data due to treatment abroad (three patients); refusal to continue treatment (one); death due to pancytopenia with MVPP (one); complete remission during third course of quadruple chemotherapy, so treatment stopped (one). $\ddagger$ One death due to cerebrovascular accident, diabetes mellitus, and nephrotic

§Inadequate records (three patients); complete remission during third course of quadruple chemotherapy, so treatment stopped (one). 
chemotherapy to this group undoubtedly contributed to their poor achievement of remission. One untreated patient was given chemotherapy inappropriately at a time of severe bone marrow suppression and died of overwhelming septicaemia.

Two patients who had received both combination chemotherapy and radiotherapy developed symptomatic osteoarthritis due to clinical avascular necrosis of the femoral heads, which was subsequently confirmed histologically after total hip replacement. ${ }^{11} 12$ In both cases the total steroid dose was less than $3.5 \mathrm{~g}$ and the radiotherapy fields included the affected hips.

\section{CAUSES OF DEATH}

Fifty-eight of the 133 patients $(44 \%$ ) with advanced HD died during the study. Necropsy reports were available in 22 cases. HD was clinically active in 54 patients $(93 \%$ ) when they died and was thought to be the principal cause of death in $40(69 \%)$. One death was directly due to pancytopenia occurring after chemotherapy. Infections complicating HD were responsible for a further nine deaths but were not necessarily associated with chemotherapy-induced cytopenia. Four patients died of other causes while in remission of HD. Five malignancies other than HD were observed. Two patients developed acute leukaemia, one developed Kaposi's sarcoma, and one patient had coexisting squamous carcinoma and adenocarcinoma of the uterine cervix and fibrosarcoma of the uterus. Another patient developed osteogenic sarcoma of the humeral head. These malignancies all occurred in patients who had previously received irradiation, either alone or with single-agent chemotherapy, and had suffered periods of active disease before beginning combination chemotherapy. ${ }^{13} 14$

\section{Discussion}

Combination chemotherapy has dramatically altered the prognosis of advanced HD. In a population of patients who had relapsed after radiotherapy or who had received no treatment $82 \%$ achieved complete remission, and the five-year survival rate was $75 \%$. An overall median survival of about 12 years is predicted. The five-year survival rate for patients in complete remission one year after entry was $92 \%$, and their disease-free survival rate at five years was $73 \%$.

The highly favourable prognosis for patients who had received prior irradiation may be explained by the predominance of younger patients and the lower incidence of stage IVB disease in this group. This perhaps reflects the earlier detection of relapse in patients already being followed up after radiotherapy. The sterilisation of tissue susceptible to HD by the previous irradiation may also be a factor. Patients who had received single-agent chemotherapy had a much poorer overall prognosis, probably because of the predominance of stage IVB disease and because effective chemotherapy could not be given to $25 \%$ of the group due to bone marrow depression. Single-agent chemotherapy is no longer a part of management protocols, however, so these patients are not discussed in detail. It should not be assumed that this group gives a representative prognosis for patients currently undergoing reinduction because of relapse after combination chemotherapy.

The major factor influencing remission rate was advanced stage of disease-that is, stage IVB. Older patients took longer to achieve remission; their remission rate was probably lower, and their mortality after relapse was higher. Histological type, sex, and presence of symptoms had little effect on prognosis. Achievement of remission was clearly the most important factor determining survival; hence advanced age and stage also adversely affected survival. After remission was achieved advanced age was the only significant prognostic factor with a noticeably adverse effect on survival and perhaps remission duration.

The MVPP regimen was satisfactorily administered to outpatients. Haematological toxicity was comparable with that of other reported regimens, and, although most patients observed the six-week cycle, up to $40 \%$ required dosage reductions or modifications. No appreciable neurotoxicity was seen. Modifying the MOPP and MVPP regimens by replacing mustine with cyclophosphamide $^{15}$ or chlorambucil ${ }^{16}$ to avoid the severe nausea and vomiting reportedly results in equivalent remission rates, although the long-term results for these regimens are not $\Phi$ yet available.

Most patients who died during the study had active HD at $\frac{3}{D}$ the time of death. Infections complicating active HD were $\stackrel{\varrho}{c}$ particularly apparent in patients who had received radiotherapy and single-agent chemotherapy. Five malignant diseases other $\stackrel{\vec{\rho}}{\rightarrow}$ than HD were seen. All occurred after combination chemo- $\overline{0}$ therapy was begun in patients who had relapsed after either 음 radiotherapy or radiotherapy and single-agent chemotherapy. ${ }^{13} 14 \mathrm{\overline { \textrm {N } }}$

Results of this study compared favourably with the excellent $\stackrel{\mathbb{D}}{a}$ results of the MOPP regimen. ${ }^{2}$ Nevertheless, three considerations may lead to further improvement-namely, better definition of remission, prolonged maintenance of remission, and $\vec{O}$ earlier recognition of patients failing to achieve remission.

Assessment of remission is currently undertaken with use of $\vec{\omega}$ clinical techniques, whose accuracies have been compared with $\frac{5}{3}$ the accuracies of laparotomy and splenectomy. The limitations of clinical investigation have been emphasised, ${ }^{9}$ and an error of $\vec{\sigma}$ $30 \%$ has been found in assessing the extent and distribution of the disease by clinical as opposed to surgical methods. ${ }^{917}$ Most relapses occur in the 18 months after the end of MVPP treatment; some of these relapses probably represent the clinical $\bullet$ appearance of minimal residual disease, which was not detected by the tests used in assessing remission. Laparoscopy is a useful $\vec{\infty}$ means of determining liver infiltration, although its value in $z$ assessing splenic and abdominal nodal disease is limited. ${ }^{1819} \frac{\mathrm{m}}{7}$ As remission is the most critical factor influencing survival it $\stackrel{\rho}{\supset}$ may be that exploratory laparotomy and splenectomy would be $\vec{\varphi}$ a more reliable means of assessing remission, and, in the event of $\infty$ detection of residual disease, further treatment by irradiation or chemotherapy could be planned.

Maintenance of remission by prolonged chemotherapy has been undertaken by two groups, with apparently conflicting results. ${ }^{520}$ Most patients undergoing a relapse do so at a site of $\frac{\mathscr{D}}{\Phi}$ bulk disease at presentation. ${ }^{5}$ It appears to be justifiable to either $\varrho$ intensify the chemotherapy at the time of remission or follow a $\overrightarrow{\overrightarrow{0}}$ chemotherapy-induced remission with radiotherapy to areas of initial disease. ${ }^{21}$ In patients already shown to have a good prognosis, however, the deleterious side effects of cumulative treatment ${ }^{1422}$ must be balanced against the potential benefits. Continuing studies may clarify this.

About $20 \%$ of patients presenting with advanced HD fail to $\div$ achieve remission with currently available chemotherapeutic agents, and their subsequent prognosis is poor. Although $\delta$ advanced age and stage of disease are associated with a lower $₹$ remission rate, their is no satisfactory way of identifying these patients. In our experience patients who do not respond to $N$ MVPP generally fail to respond to any subsequent chemothera- $\sigma$ peutic modifications. The initial identification of such patients would permit the earlier application of a combination of radiotherapy and chemotherapy. It would also afford a more $\mathrm{N}$ realistic prognosis based on their particular survival pattern $\underset{\omega}{ }$ rather than on that of all patients with advanced HD.

This work was initiated and carried out under the direction of the late Professor Gordon Hamilton Fairley.

Requests for reprints should be addressed to: Dr S B Sutcliffe, $T$ ICRF Department of Medical Oncology, St Bartholomew's Hospital, London EC1A 7BE.

\section{References}

1 DeVita, V T, et al, Annals of Internal Medicine, 1970, 73, 881.

2 DeVita, V T, et al, Cancer, 1972, 30, 1495.

3 Moore, M R, et al, Cancer, 1973, 32, 52.

4 Nixon, D W, and Aisenberg, A C, Cancer, 1974, 33, 1499.

5 Frei, E M, III, et al, Annals of Internal Medicine, 1973, 79, 376.

6 Nicholson, W M, et al, British Medical fournal, 1970, 11, 7.

7 Rosenberg, S A, Cancer Research, 1971, 31, 1862. 
${ }^{*}$ Lukes, R J, et al, Cancer Research, 1971, 31, 1755.

${ }^{9}$ Sutcliffe, S B J, et al, British Medical fournal, 1976, 2, 1343.

${ }^{10}$ Peto, R, et al, British fournal of Cancer, 1976, 34, 585.

11 Timothy, A R, et al, British fournal of Radiology. In press.

12 Ihde, D C, et al, Cancer, 1975, 36, 1585.

${ }^{13}$ Arceneau, J C, et al, New England fournal of Medicine, 1972, 287, 1119.

${ }^{4}$ Canellos, G P, et al, Lancet, 1975, 1, 947.

${ }^{15}$ Bloomfield, C D, et al, Cancer, 1976, 38, 42

${ }^{16}$ McElwain, T, et al, British fournal of Cancer, 1977, 36, 276.
17 Glatstein, E, et al, Cancer, 1969, 24, 709.

18 Bagley, G M, et al, Cancer, 1973, 31, 840.

19 Spinelli, P, British Medical fournal, 1975, 4, 554.

20 Young, R C, et al, Lancet, 1973, 1, 1339.

21 Prosnitz, L R, et al, Radiology, 1973, 107, 187.

${ }^{22}$ Kun, L E, et al, International fournal of Radiation Oncology-Biology and Physics, 1975, 1, 619.

(Accepted 21 December 1977)

\title{
Intramuscular injections of iron compounds and oncogenesis in man
}

\author{
K WEINBREN， R SALM， G GREENBERG
}

British Medical Fournal, 1978, 1, 683-685

\section{Summary and conclusions}

To evaluate the evidence for iron compounds as local carcinogens in man, histological material and clinical reports have been reviewed in seven of the eight published cases of tumours developing at the site of intramuscular injections. The microscopical appearances suggested benign lesions in two cases and a variety of tumours in the other five. In only two cases (a rhabdomyosarcoma and a fibrosarcoma) was the interval between injections and tumour development longer than six years. Of the remaining three tumours, one was considered to be a rather slowly growing haemangiopericytoma (with an interval of two years), one appeared to be a subcutaneous lymphoma with no evidence of having arisen in the gluteal muscles, and one was a pleomorphic sarcoma with a possible five-year interval. Sarcomas induced experi-

Department of Histopathology, Royal Postgraduate Medical School, London W12 0HS

$\mathrm{K}$ WEINBREN, MD, FRCPATH, professor of histopathology

Hammersmith Hospital, London W12 0HS

R SALM, MD, FRCPATH, honorary consultant histopathologist

Medicines Division, Department of Health and Social Security, London EC2A 1PP

GILLIAN GREENBERG, MB, BS, senior medical officer mentally by iron compounds differ in being less variable in type and in containing abundant iron-containing macrophages, which were negligible in these human tumours.

Although the total number of patients who have received intramuscular injections of iron compounds is not known, the present findings, in contrast to experimental work, do not support the view that such treatment carries a strong risk of tumour development.

\section{Introduction}

Injections of some iron compounds in rodents and rabbits are associated with the development of sarcoma at the injection sites. ${ }^{1-4}$ These compounds have now been in clinical use for more than 20 years, long enough for tumours to have become apparent ${ }^{5}$ if these compounds are carcinogenic in man. There have been sporadic case reports, all but one from the United Kingdom, of tumours at previous injection sites. ${ }^{6-9}$ But whereas the experimentally induced tumours have been of similar appearance, ${ }^{10}$ the human tumour types have varied considerably. We have therefore reviewed the available material and case reports to assess whether the tumours were indeed likely to have been induced by iron injections.

\section{Review of cases}

Through the kindness of clinicians and pathologists we acquired material from seven of the total of eight published cases, and further clinical details about three of the patients (table).

Summary of 8 case reports of buttock sarcomas after intramuscular iron iniections

\begin{tabular}{|c|c|c|c|c|c|c|c|c|}
\hline $\begin{array}{l}\text { Case } \\
\text { No }\end{array}$ & Source & $\begin{array}{l}\text { Patient's } \\
\text { age } \\
\text { and sex }\end{array}$ & $\begin{array}{c}\text { Compounds } \\
\text { used }\end{array}$ & $\begin{array}{l}\text { Injection } \\
\text { sites }\end{array}$ & $\begin{array}{c}\text { Interval } \\
\text { after } \\
\text { injections } \\
\text { (years) }\end{array}$ & $\begin{array}{r}\text { Original } \\
\text { diagnosis }\end{array}$ & $\begin{array}{l}\text { Opinion on } \\
\text { review }\end{array}$ & Remarks \\
\hline 1 & Robinson et al & $74 \mathrm{~F}$ & Iron dextran & Left deltoid & 4 & Undifferentiated & Chronic inflammatory & Case excluded \\
\hline 2 & MacKinnon and & $73 \mathrm{~F}$ & $\begin{array}{l}\text { Jectofer* and } \\
\text { iron } \\
\text { dextran }\end{array}$ & Buttocks & 6 & $\begin{array}{l}\text { Reticulum-cell } \\
\text { sarcoma }\end{array}$ & $\begin{array}{l}\text { Reticulum-cell } \\
\text { sarcoma }\end{array}$ & $\begin{array}{l}\text { Subcutaneous } \\
\text { lymphoma; no } \\
\text { tumour remaining }\end{array}$ \\
\hline 3 & & $25 \mathrm{~F}$ & $\begin{array}{l}\text { Iron dextran } \\
(2 \text { courses })\end{array}$ & Buttocks & 5 and 2 & $\begin{array}{l}\text { Pleomorphic } \\
\text { sarcoma }\end{array}$ & $\begin{array}{l}\text { Pleomorphic } \\
\text { sarcoma }\end{array}$ & \\
\hline 4 & & $18 \mathrm{M}$ & Jectofer & Buttock & 2 & Fibrosarcoma & $\begin{array}{l}\text { Haemangiopericytoma } \\
\text { or mesenchymal } \\
\text { chondrosarcoma }\end{array}$ & \\
\hline 5 & Greenberg" & $40 \mathrm{~F}$ & Jectofer & Not recorded & 4 & Liposarcoma & Benign myxoma of & Case excluded \\
\hline $\begin{array}{l}6 \\
7\end{array}$ & & $\begin{array}{l}35 \mathrm{~F} \\
51 \mathrm{~F}\end{array}$ & $\begin{array}{l}\text { Iron dextran } \\
\text { "Iron" }\end{array}$ & $\begin{array}{l}\text { Not recorded } \\
\text { Buttock }\end{array}$ & "Several & $\begin{array}{l}\text { Rhabdomyosarcoma } \\
\text { Chondrosarcoma }\end{array}$ & $\begin{array}{l}\text { Rhabdomyosarcoma } \\
\text { Not examined }\end{array}$ & Case excluded \\
\hline 8 & Robertson and Dick ${ }^{9}$ & $35 \mathrm{~F}$ & Iron dextran & Buttocks & $\underset{14}{\text { month }}$ & Fibrosarcoma & Fibrosarcoma & \\
\hline
\end{tabular}

*Iron sorbitol and citric acid complex. 